\title{
Synovial Hemangioma
}

National Cancer Institute

\section{Source}

National Cancer Institute. Synovial Hemangioma. NCI Thesaurus. Code C6525.

A rare hemangioma arising from synovium lining surfaces. 